\title{
O PAPEL DO GESTOR ESCOLAR: ESTUDO DE CASO SOBRE OS DESAFIOS DA EDUCAÇÃO PÚBLICA
}

\author{
EL PAPEL DEL GESTOR ESCOLAR: ESTUDIO DE CASO SOBRE LOS DESAFÍOS \\ DE LA EDUCACIÓN PÚBLICA
}

\section{THE ROLE OF THE SCHOOL MANAGER: CASE STUDY ON THE CHALLENGES OF PUBLIC EDUCATION}

\author{
Vanise Panont do NASCIMENTO ${ }^{1}$ \\ Cláudio Luiz CHIUSOLI ${ }^{2}$
}

\begin{abstract}
RESUMO: O presente artigo diz respeito a um estudo de caso sobre o papel do gestor escolar frente aos principais desafios da educação pública atual e como trabalha para tentar solucionar tais desafios. Desta forma, foi realizada uma entrevista com uma gestora escolar para entender o seu papel e identificar os principais desafios encontrados atualmente na educação pública em período integral. Assim sendo, os resultados alcançados foram que os desafios na gestão pública escolar estão relacionados com os problemas sociais e familiares de cada aluno, com a irregularidade dos recursos financeiros, com a falta de pessoal para trabalhar, tanto de professoras, como de serviços gerais, a falta de autonomia da gestora, a dificuldade em manter a equipe motivada, o excesso de projetos e a rotatividade de pessoal. Para solucionar tais desafios, a gestora conta com a participação efetiva dos pais, professores, funcionários, comunidade e poder público.
\end{abstract}

PALAVRAS-CHAVE: Educação. Escola pública. Gestor escolar.

RESUMEN: El presente artículo dice respecto a un estudio de caso sobre el papel del gestor escolar ante los principales desafíos de la educación pública actual y cómo trabaja para intentar solucionar tales desafíos. De esta forma, fue realizada una encuesta con una gestora escolar para comprender a su papel e identificar a los principales desafios encontrados actualmente en la educación pública en periodo integral. Así siendo, los resultados logrados fueron que los desafíos en la gestión pública escolar están relacionados con los problemas sociales y familiares de cada alumno, con la irregularidad de los recursos financieros, con la falta de personal para trabajar, tanto de profesoras, como de servicios generales, la falta de autonomía de la gestora, la dificultad en mantener el equipo motivado, el exceso de proyectos y la rotación de personal. Para solucionar tales desafíos, la gestora cuenta con la participación efectiva del padres, profesores, empleados, comunidad y poder público.

PALABRAS CLAVE: Educación. Escuela pública. Gestor escolar.

\footnotetext{
${ }^{1}$ Universidade Estadual do Centro Oeste do Paraná (UNICENTRO) Guarapuava - PR - Brasil. Bacharel em Turismo e em Direito. Especialista em Gestão Pública. ORCID: <https://orcid.org/0000-0003-0100-8808>. Email: vapanont@hotmail.com.

${ }^{2}$ Universidade Estadual do Centro Oeste do Paraná (UNICENTRO) Guarapuava - PR - Brasil. Professor Orientador. Pós doutor pela PUCPR (Ctba) e Doutor em Administração. Departamento de Administração. ORCID: <https://orcid.org/0000-0002-7844-3632. E-mail: prof.claudio.unicentro@gmail.com.
} 
ABSTRACT: This article relates to a case study on the role of the schools manager facing the main challenges of current public education and how they work to try to resolve these challenges. This way, was conducted an interview with a school manager to understand their role and to identify the main challenges faced today in public education on a full-time basis. Thus, the results achieved were that the main challenges in public management at school are related with the social and family problems of each student, with the irregularity of financial resources, with the lack of personnel to work, both of teachers, as general services, the lack of autonomy of the manager, the difficulty in keeping the team motivated, the excess of projects and staff turnover. To solve these challenges, the manager counts with the participation of parents, teachers, staff, community and public power.

KEYWORDS: Education. Public school. School manager.

\section{Introdução}

A educação é a base de tudo na vida do homem, importante para o seu desenvolvimento humano e em sociedade. Com o conhecimento, o homem pode ir além de suas expectativas de vida, ultrapassar fronteiras, ajudar o próximo a se desenvolver e ter uma melhor qualidade de vida. Para Freire (1979), a educação é uma resposta da finitude da infinitude, uma vez que a educação é possível para o homem porque este é inacabado e sabe-se inacabado; isto leva-o à sua perfeição.

Ferreira (2003) complementa que a escola tem um papel fundamental na vida social dos indivíduos. Desta forma, a educação é primordial e faz-se necessária na atividade humana. Escrever sobre a educação é sempre relevante, ainda mais quando se trata da educação pública no Brasil, e descobrir quais os principais desafios que o gestor de uma escola pública enfrenta atualmente é muito difícil, em se tratando que o cargo de gestor é ainda, na maioria das escolas públicas, um cargo político; assim sendo, muitos gestores podem temer em falar realmente o que pensam e o que têm vontade.

Lück (2009, p. 24) explica o significado de gestão escolar, que é o ato de gerir a dinâmica cultural da escola, afinado com as diretrizes e políticas educacionais públicas para a implementação de seu projeto político-pedagógico e compromissado com os princípios da democracia e com os métodos que organizem e criem condições para um ambiente educacional autônomo (soluções próprias, no âmbito de suas competências), de participação e compartilhamento (tomada de decisões conjunta e efetivação de resultados) e autocontrole (acompanhamento e avaliação com retorno de informações). 
Atualmente, é muito falado sobre a gestão escolar democrática, a qual Paro (2003) escreve ser utópica, visto que toda vez que se propõe uma gestão democrática da escola pública, que tenha efetiva participação de pais, educadores, alunos e funcionários da escola, isso acaba sendo considerado como coisa utópica. O município investigado conta atualmente com trinta e sete escolas municipais, sendo trinta e duas em tempo integral, e cinco em tempo parcial, todas sob o comando da Autarquia Municipal de Educação.

O presente trabalho justifica-se pela importância da educação pública para a sociedade e os principais desafios que o gestor escolar, como administrador da escola, enfrenta nos dias de hoje para garantir um ensino de qualidade aos alunos, o bom andamento da instituição de ensino e do funcionamento do prédio escolar. Dessa forma, a questão norteadora do estudo é: quais os principais desafios que o gestor de uma escola pública municipal enfrenta atualmente e como tenta solucionar tais desafios?

O objetivo geral do trabalho é identificar e descrever os principais desafios que o gestor de uma escola pública municipal enfrenta atualmente e como trabalha para tentar solucionar tais desafios.

\section{Aspectos históricos e conceitos sobre o tema}

Miranda (2003) cita que a administração escolar se assume diretamente como um ato administrativo de um conteúdo que tem uma outra face, que é o processo de ensino e aprendizagem em uma instituição acadêmica. Ferreira (2003) entende que a gestão da educação é a tomada de decisões conscientes sobre o que trazer a partir de objetivos definidos. Necessário se faz entender que toda a tomada de decisões é um pensar político e um ato político, porque implica em escolhas que se faz entre opções existentes e onde se quer chegar.

Segundo Lück (2009), ao gestor escolar compete a liderança e organização do trabalho de todos os que nela atuam, de modo a orientá-los no desenvolvimento de um ambiente educacional capaz de promover aprendizagens e formação dos alunos, no nível mais elevado possível, de maneira que estejam capacitados a enfrentar os novos desafios que são apresentados.

Gracindo (2009) expõe em seu artigo que a escola é um espaço de exercício democrático, e que a democracia deve fazer parte da postura do gestor escolar, o qual tem o dever de trazer para dentro da escola o poder público, a comunidade e o coletivo escolar para participarem do cotidiano. A respeito da autonomia da escola, Ferreira (2003) explica que a 
escola deve alicerçar o conceito de autonomia, enfatizando a responsabilidade de todos, sem deixar de lado os outros níveis da esfera administrativa educacional. A autonomia, desta forma, é peça fundamental para a criação da identidade da escola.

Werle (2001), em seu artigo, descreve a diferença das designações de diretor, administrador e gestor escolar. Segundo a autora, o diretor é assim chamado popularmente e representa uma posição hierárquica; o administrador escolar está mais voltado para quem cuida da administração da instituição e representa mais o nível técnico do cargo; e o gestor escolar é mais abrangente, compreende a função exercida no geral dentro da escola. Assim sendo, o próximo tópico irá aprofundar mais sobre os aspectos históricos e conceituais da educação no Brasil e do papel do gestor escolar atualmente. A escola possui um papel fundamental na sociedade, e o gestor escolar tem em suas mãos o poder de dirigir a instituição de ensino, conforme a legislação estabelece, e fazer a ligação escola-comunidade. Segundo Freire (1979), a educação é possível para o homem pois este é um sujeito inacabado, isto leva-o a sua perfeição. Assim sendo, o homem deve ser sujeito de sua educação, e não objeto dela.

Em relação aos aspectos históricos, Pasquini e Souza (2012, p. 17), em sua obra, descrevem que a partir do final da década de 1980, período marcado pela redemocratização do nosso país, a gestão democrática da educação e da escola pública tornou-se o centro do debate educacional. Esse período histórico, que representou o fim de um regime militar de duas décadas, foi marcado por um sentimento de esperança por um Brasil mais justo e desenvolvido, cuja principal bandeira era uma educação de qualidade para o povo brasileiro, por meio da qual o país alcançaria credibilidade e a inserção no mercado mundial. Porém, a história nos revela outra face não tão animadora. A educação não foi priorizada, o que vimos foi o sucateamento da escola pública e a desvalorização dos profissionais da educação. Foi neste contexto que, a partir da Constituição Federal (CF) de 1988, a gestão democrática foi eleita como tema fundamental para a melhoria na qualidade de ensino público.

Desta forma, no capítulo III, seção I da Constituição da República Federativa do Brasil, no artigo 205 cita que a educação é direito de todos e dever do Estado e da família, visando ao pleno desenvolvimento da pessoa, seu preparo para o exercício da cidadania e sua qualificação para o trabalho e no artigo 206 estabelece que o ensino será ministrado com base nos seguintes princípios: i) igualdade de condições para o acesso e permanência na escola; ii) liberdade de aprender, ensinar, pesquisar e divulgar o pensamento; iii) pluralismo de ideias e de concepções pedagógicas, e coexistência de instituições públicas e privadas de ensino; iv) gratuidade do ensino público em estabelecimentos oficiais; v) valorização dos profissionais da educação 
escolar, planos de carreira, com ingresso exclusivamente por concurso público de provas e títulos, aos das redes públicas; vi) gestão democrática do ensino público; vii) garantia de padrão de qualidade; viii) piso salarial profissional nacional para os profissionais da educação escolar pública (BRASIL, 1988).

Verifica-se assim que a partir da promulgação da Constituição Federal de 1988 no Brasil, a educação ganha um caráter democrático, conforme o inciso VI, e desde então vem sendo construída. Uma tarefa difícil para um país que viveu sob um forte e longo período de regime militar. De acordo com Paro (2003), na medida em que se conseguir a participação de todos os setores da escola - educadores, alunos, funcionários e pais - nas decisões sobre seus objetivos e seu funcionamento, haverá melhores condições para pressionar os escalões superiores a dotar a escola de autonomia e de recursos.

A gestão democrática escolar é algo que vem sendo trabalhado dia após dia no espaço escolar e é formada pela participação efetiva de pais, professores, alunos e funcionários da escola, portanto as decisões não estão apenas nas mãos do diretor escolar, e sim de toda a comunidade escolar, tendo o gestor um papel intermediador, articulador.

A lei 9394 (BRASIL, 1996) estabelece as diretrizes e bases da educação nacional, e no artigo 14 rege sobre a gestão democrática que versa: i) participação dos profissionais da educação na elaboração do projeto pedagógico da escola e ii) participação das comunidades escolar e local em conselhos escolares ou equivalentes.

Paro (2003) ainda explica que a democracia, enquanto valor universal e prática de colaboração recíproca entre grupos e pessoas, é um processo globalizante que, tendencialmente, deve envolver cada indivíduo, na plenitude de sua personalidade. Não pode haver democracia plena sem pessoas democráticas para exercê-la. A escola pública deve se adequar aos interesses das camadas trabalhadoras, e para isso deve desenvolver meios que estimulem e facilitem a participação dos pais e da comunidade em geral para as tomadas de decisões (PARO).

Nesta linha de raciocínio, Paro (2003) explana que a participação da população nas decisões que se tomam na escola ganha sentido diante a necessidade de que o caminho para uma sociedade verdadeiramente democrática não se restrinja ao voto periódico para os ocupantes de cargos parlamentares e executivos do Estado. Para que se sinta pressionado a agir em benefício dos interesses dos cidadãos, é preciso que se proceda ao seu controle democrático.

Sobre o papel dos gestores escolares, Lück (2012) explica que o trabalho dos gestores escolares se assenta, pois, sobre sua capacidade de liderança, isto é, de influenciar a atuação de pessoas (professores, funcionários, alunos, pais) para a efetivação dos objetivos educacionais 
propostos pela escola. A liderança deve fazer parte da vivência de qualquer profissional que desempenha função relacionada a outros seres humanos. Os líderes são responsabilizados pelo sucesso ou fracasso de qualquer ação realizada pelo grupo. Por isso, liderar não é uma tarefa simples. Liderança exige confiança, paciência, disciplina, humildade, respeito e compromisso (MEDEIROS et al., 2009).

Ainda descrevendo sobre a liderança do gestor escolar, Lück (2012) afirma que a liderança na escola é uma característica inerente à gestão escolar pela qual o gestor mobiliza, orienta e coordena o trabalho de pessoas para aplicarem o melhor de si na realização de ações de caráter sociocultural voltadas para a contínua melhoria da qualidade do ensino e da aprendizagem, ela se assenta sobre uma atitude proativa, pelo entusiasmo e elevadas expectativas do gestor em sua capacidade de influenciar essa atuação e seus resultados.

Lück (2012) explica que a gestão escolar pressupõe o trabalho com outras dimensões, como, por exemplo, a gestão administrativa, gestão de currículo, gestão de resultados etc. Desta maneira, identifica-se que os conceitos de gestão e de liderança não são sinônimos, mas se complementam e podem até ser confundidos como sendo a mesma expressão (LÜCK).

O gestor escolar pode também ser chamado de administrador escolar, "devido ao seu gerenciamento, assume a responsabilidade sobre as atividades desenvolvidas e os atos praticados na gestão, devendo, portanto, possuir conhecimento amplo de tudo o que está relacionado a essa entidade (MEDEIROS et al., 2009). Valerien (2001) expõem que o diretor de escola vem assumindo, pouco a pouco, importância cada vez maior na administração. Progressivamente, ele foi levado a desempenhar, num certo sentido, todas as funções. Esta nova realidade implica que sejam redefinidas suas atribuições, a fim de que sejam evitados choques de competência. Por um lado, o poder do diretor de escola é proporcional ao do supervisor; por outro, ao dos professores.

Como o gestor escolar é equiparado ao administrador, importante definir que "o termo administração pode ser entendido como um conjunto de princípios, normas e funções que têm por fim ordenar os fatores de produção e controlar sua produtividade e eficácia, obtendo determinado resultado (MEDEIROS et al., 2009).

O resultado, neste caso, não significa o lucro financeiro, e sim a formação do ser humano, sua formação educacional e social. Deste modo, a gestão da escola pública trata-se de uma maneira de organizar o funcionamento da instituição quanto aos aspectos políticos, administrativos, financeiros e pedagógicos, com a finalidade de dar transparência às suas ações e atos e possibilitar à comunidade escolar e local a aquisição de conhecimentos, saberes, ideias 
e sonhos num processo de apresentar, inventar, criar, dialogar, construir, transformar e ensinar (MEDEIROS et al., 2009).

Importante destacar também sobre o clima e a cultura organizacional no ambiente escolar. De acordo com Lück (2011), o clima e a cultura organizacional de uma escola são formados ao longo da história do estabelecimento de ensino em sua vinculação externa com a comunidade e o sistema de ensino de que faz parte, mediante a dinâmica de interações internas, que marca, de maneira indelével, o modo como os desafios, estimulações e demandas são enfrentados, como as pessoas os percebem e como reagem diante deles, dentre outros aspectos.

Neste sentido, Lück (2011) afirma que o trabalho do gestor escolar está intimamente ligado com o clima e a cultura organizacional, visto que ele trabalha para e pela equipe escolar, intermediando suas relações grupais e interpessoais, seus humores, entre outros.

Lück (2011) alerta ainda que a atuação do gestor escolar ocorre não necessariamente no clima e na cultura organizacional da escola, como um todo, mas num campo de tensões e conflitos entre o que a escola é e o que deve ser, entre grupos diferentes.

Desta forma, observa-se que assim como a liderança é inerente ao papel do gestor, aprender a trabalhar com o clima e a cultura organizacional também é atividade inerente de sua profissão, mas ambas são essenciais para um bom desenvolvimento na gestão.

\section{Estudos Semelhantes}

Paro (2003) descreve sobre a utopia da gestão escolar democrática, uma vez que entende a dificuldade que é para o gestor escolar fazer com que os pais, os alunos, os professores e a comunidade participem efetivamente das decisões que a escola deve tomar e sobre a transformação da autoridade escolar.

Cita também Paro (2003) em sua obra sobre a falta de autonomia do gestor escolar, e neste sentido descreve que essa impotência e falta de autonomia do diretor sintetizam a impotência e falta de autonomia da própria escola. E se a escola não tem autonomia, é o próprio trabalhador, enquanto usuário, que fica privado de uma das instâncias por meio das quais ele poderia apropriar-se do saber e da consciência crítica. Essa autonomia, esse poder, só se dará como conquista das camadas trabalhadoras. Por isso, é preciso com elas buscar a reorganização da autoridade no interior da escola. Bortolini (2013) explica ainda que a autonomia da escola está relacionada com a potencialidade que a escola possui em elaborar e executar seus projetos, envolvendo a escola e a comunidade, e que o objetivo é sempre melhorar a qualidade de ensino. 
Como consequência desta autonomia, a escola deverá prestar contas para a comunidade, e este ato resulta em uma gestão democrática. Desta maneira, verifica-se algumas das dificuldades que o gestor escolar enfrenta na educação pública: uma é a gestão democrática por meio da participação efetiva de todos os envolvidos; e a outra é a falta de autonomia que o gestor escolar possui para liderar sua equipe.

Nessler e Miranda (2013) elaboraram um estudo de caso com uma escola pública municipal da cidade de Três Passos, no Rio Grande do Sul, para identificar os principais desafios do gestor escolar na função de direção; e Fialho E Tsukamoto (2014) aplicaram questionários semiestruturados em oito gestores escolares da cidade de Curitiba, no Paraná, questionando-os sobre quais os principais desafios do gestor escolar na gestão democrática brasileira para um ensino de qualidade. No estudo de Nessler e Miranda (2013), os resultados encontrados apontam a falta de recursos humanos, ou seja, falta de mais pessoas, tanto de zeladoras quanto de professores para atenderem melhor os alunos, com atendimento individualizado, reforço, entre outros, e também no administrativo, onde a equipe diretiva é formada apenas por duas pessoas, a diretora e a coordenadora, as quais são responsáveis por toda a parte administrativa e pedagógica da escola. Outras dificuldades apontadas pela gestora são: a falta de recursos financeiros, a qual inviabiliza a execução de programas e projetos, a dificuldade de envolver a comunidade e as professoras nas decisões escolares, devido a dificuldade de bater os horários; problemas na infraestrutura do prédio escolar; a falta de tempo em relação a quantidade de trabalho; a burocracia para gastar as verbas federais; e a dificuldade em motivar o trabalho em equipe como um todo.

Já no estudo de Fialho e Tsukamoto (2014), as pesquisadoras entrevistaram oito gestores escolares da cidade de Curitiba, e os resultados apontaram que, em ordem de relevância, a maioria considera mais importante a parte pedagógica, onde ensinar o aluno é o foco principal da educação; na sequência, a interação com a comunidade, na qual educar é responsabilidade de todos, e não apenas da escola; em seguida, o setor administrativo; posteriormente a obtenção de recursos físicos e financeiros para implementar ações pedagógicas; e, por último, o relacionamento do gestor com o aluno, e do gestor com o professor. Neste mesmo artigo, Fialho e Tsukamoto (2014) também fizeram perguntas abertas, ou para aprofundar o estudo. Na primeira questão foi solicitado um comentário sobre a participação das gestoras no Projeto Político Pedagógico, onde a maioria relatou ser muito importante a participação do gestor escolar na elaboração deste; e o segundo questionamento foi a respeito dos maiores desafios como gestores escolares atualmente, e os respondentes relacionaram a falta de recursos físicos 
e financeiros, o desestímulo do corpo docente, a dificuldade de participação da comunidade e a relação dos professores com a comunidade. Desta forma, com o uso de metodologias diferentes, foram identificados diversos desafios e problemas enfrentados pelos gestores escolares atualmente.

\section{Metodologia da pesquisa}

O método utilizado para este estudo foi a pesquisa qualitativa, mediante entrevista em profundidade. De acordo com Dencker (2001), a pesquisa qualitativa é adequada para se obter um conhecimento mais profundo de casos específicos, porém não permite a generalização em termos de probabilidade de ocorrência. A pesquisa bibliográfica tem como base livros e artigos científicos, a qual é de muita valia para a pesquisa, em especial para o referencial teórico, pois possibilitou abranger os estudos e ter uma visão além das fronteiras do conhecimento, tendo ideias de diferentes autores sobre um determinado assunto. De acordo com Martins (2002), a pesquisa bibliográfica tem como objetivo recolher, selecionar e interpretar as contribuições teóricas já existentes sobre determinado assunto. Barros e Lehfeld (2000) ainda citam que este tipo de pesquisa é importante porque lhe permite obter uma postura quanto à elaboração de informações da produção científica já existente. Outro tipo de pesquisa para o estudo foi o exploratório, que para Dencker (2001) caracteriza-se por possuir um planejamento flexível envolvendo, em geral, levantamento bibliográfico, entrevistas com pessoas experientes e análise de exemplos similares. Quanto aos objetivos da pesquisa, foi utilizada a pesquisa explicativa, que de acordo com Zanella (2012) é aquela centrada na preocupação de identificar fatores determinantes ou contributivos ao desencadeamento dos fenômenos. Explicar a razão do fato ou fenômeno social. Também é importante situar o ambiente social da ocorrência. Em relação aos procedimentos adotados para a coleta de dados, foi realizado um estudo de caso, que segundo Zanella (2012) é uma forma de pesquisa que aborda com profundidade um ou poucos objetos de pesquisa, por isso tem grande profundidade e pequena amplitude, procurando conhecer em profundidade a realidade de uma pessoa ou de um grupo de pessoas. Desta maneira, foi realizada entrevista com uma diretora de uma escola pública municipal da cidade no mês de setembro de 2017. O roteiro dessa pesquisa, o qual foi aplicado a entrevista, continha vinte perguntas relacionadas ao tema proposto. As perguntas versavam a respeito das seguintes variáveis, a escolha do cargo de direção, as funções e o papel do gestor escolar, a formação da equipe gestora, gestão democrática, liderança na gestão, participação da comunidade, pais e 
professores na escola, autonomia da gestora, formação do conselho escolar, recursos humanos, recursos financeiros, motivação da equipe, ensino de qualidade e os principais desafios para gerir uma escola pública em tempo integral nos dias de hoje.

\section{Resultados e discussão}

A instituição de ensino escolhida é uma das trinta e sete escolas municipais e está sob o comando da Autarquia Municipal de Educação. Funciona em período integral; atende em média duzentas e quarenta crianças do Pré I ao $5^{\circ}$ ano do ensino fundamental; possui sala de recursos multifuncional; participa do programa mais educação do Governo Federal; conta atualmente com dez professores graduados e alguns pós-graduados, sete auxiliares de serviços gerais com ensino fundamental e médio; na equipe gestora conta com uma secretária, uma coordenadora e uma diretora, todas pós-graduadas. Com o intuito de evitar constrangimentos futuros, optou-se por não serem citados nomes, nem da instituição de ensino e nem da gestora entrevistada.

Em relação a entrevista realizada com a diretora escolar, a primeira pergunta foi o tempo de carreira que possui, esta respondeu que tem mais de vinte anos de carreira como professora, sendo destes cinco anos de gestão escolar. Na sequência, foi questionada sobre como é feita a escolha para o cargo de direção na escola e no município, ela respondeu que o cargo ainda não é eletivo, e sim político, portanto a escolha é feita pelo prefeito da cidade, o qual nomeia através de portaria. De acordo com Paro (2003), quando um gestor escolar não é eleito pela comunidade escolar, mas sim escolhido conforme interesse político-partidário, isso contraria os interesses de seus usuários. Em seguida, foi perguntado sobre quais são, na opinião dela, as funções do gestor escolar e qual o papel deste para a comunidade; a diretora respondeu que o gestor escolar possui funções pedagógicas, de gestão de pessoas e financeira, além de cuidar da estrutura e funcionamento geral da escola, e que, para a comunidade, é um representante do prefeito, uma vez que as pessoas se dirigem a ela quando possuem algum problema no bairro. Segundo Wittmann (2004), as funções do gestor escolar estão atreladas à competência técnicoadministrativa, representatividade político-comunitária e compromisso púbico-educativo.

Na sequência, foi questionada de como é formada a equipe gestora de sua escola e qual a função de cada um; ela respondeu que é formada pela diretora, a qual tem o dever de cuidar da escola como um todo, pela secretária, a qual cuida da documentação no geral e que, na ausência da diretora, responde pela escola, e pela coordenadora, a qual cuida da parte pedagógica da escola e da relação professores, alunos e pais. 
Lück (2009) afirma que nessa equipe de gestão tem destaque o diretor escolar, responsável maior pelo norteamento do modo de ser e de fazer da escola e seus resultados. Ela é também diretamente formada por diretores assistentes ou auxiliares, coordenadores pedagógicos, supervisores, orientadores educacionais e secretários escolares. Desta forma, Wittmann (2004) complementa que o compartilhamento da equipe gestora resulta do ambiente democrático vigente na escola e favorece e amplia este ambiente, num processo de progressiva democratização. O quinto questionamento foi sobre o que a diretora compreendia por gestão democrática; esta respondeu que é aquela onde todos (pais, professores, funcionários, comunidade escolar e sociedade civil organizada) participam efetivamente. Acrescentou ainda que na gestão democrática a decisão deve ser tomada em conjunto, e não apenas pelo gestor escolar. Paro (2003) ressalta que a gestão democrática deve implicar necessariamente na participação da comunidade na gestão da escola pública.

Considerando suas ações como gestora, foi questionada se ela se considera democrática e se considera que a Autarquia Municipal de Educação possui uma gestão democrática, a diretora respondeu que não se considera democrática, visto que acaba tomando muitas decisões sozinha, até mesmo por falta de tempo em reunir pais, professores, funcionários e a comunidade para discutir, e que também não considera a Autarquia de Educação democrática, pois para haver democracia todos precisam ser ouvidos e todos podem participar, e isto ainda não acontece na sua integralidade.

Como ela não se considera uma gestora democrática, foi questionada o que lhe impede de colocar em prática a gestão democrática e quais os maiores problemas enfrentados; ela respondeu que a gestão escolar é atrelada à gestão da Autarquia de Educação, a qual não é, na maioria das vezes, democrática, tendo em vista que existe uma verticalização das ordens, onde a Autarquia manda, e a escola obedece, sendo que, muitas vezes, o que eles mandam não faz jus a realidade da unidade escolar. O próximo questionamento foi se existe apoio da Autarquia de Educação quanto a resolução de problemas e tomada de decisões da escola; a diretora respondeu que depende do caso, se for de interesse deles sim, caso contrário não. Em relação a comunidade onde a escola está inserida, foi questionado se a mesma possui um bom relacionamento com os moradores; a diretora respondeu que sim, que a comunidade é bem participativa nas questões escolares, até porque, em torno de $70 \%$ dos alunos moram no bairro. Saindo um pouco da questão da gestão democrática, o próximo questionamento foi se a diretora se considera uma líder; ela respondeu que não, pois sua formação é de professora e a direção da escola foi apenas uma consequência dos anos de trabalho. 
Já Lück (2012) afirma em sua obra que gestão e liderança se complementam, e que para ser gestor faz-se necessário ser um líder. Como gestora escolar, foi questionada se possui autonomia para liderar, para formar sua equipe, para resolver problemas e para tomar decisões; ela respondeu que para liderar sim, para formar equipe não, para resolver problemas sim e que para tomar decisões não, pois quem forma a equipe e quem toma as decisões na escola é a Autarquia de Educação e que nem sempre a gestora escolar é ouvida.

Paro (2003) destaca em sua obra que a falta de autonomia do gestor escolar reflete na falta de autonomia da escola, limitando assim o poder de transformação que a escola possui na sociedade. Em seguida, foi questionada se na escola onde trabalha há um conselho escolar estruturado, como ele funciona, quem são os integrantes, quantos encontros são realizados por ano e se o conselho auxilia na resolução de problemas e na proposta de novas metas; a diretora respondeu que existe um conselho escolar, funciona de acordo com o estatuto, os integrantes são pais de alunos, professores, funcionários da escola e membros da sociedade civil organizada. São realizados cinco encontros por ano e que auxiliam na resolução de problemas e na proposta de novas metas sim.

Paro (2003) afirma que a instalação de um conselho de escola, constituído por representantes eleitos pelos vários setores da escola, com efetiva função de direção em regime de cooperação entre seus membros, parece ser uma medida que avança bastante no sentido de superar a atual direção monocrática da escola pública. Wittmann (2004), ainda complementa sobre o conselho escolar que os órgãos colegiados, com a contribuição dos pais, de representantes das organizações da comunidade, têm um papel importante na elaboração, execução e avaliação da proposta pedagógico-didática da escola.

Na sequência foi perguntado se o grupo docente participa, e de que forma, da elaboração e execução do plano de trabalho; a diretora respondeu que participam por meio de reuniões, apontando sugestões e por meio do conselho escolar. A próxima questão foi se os pais são participativos na vida escolar, a diretora respondeu que a maioria sim, mas que ainda existem casos em que a família não participa de nada do cotidiano escolar. Em relação aos recursos humanos, foi questionado se existem professores e funcionários em quantidade suficiente na escola, se não, quais as dificuldades encontradas com a falta de pessoal; a gestora respondeu que não possui professores e funcionários em quantidade suficiente e que as dificuldades existentes são para a manutenção da limpeza do prédio escolar, a falta de professores no aprendizado dos alunos e para substituir quando algum professor tem compromisso e precisa se ausentar da instituição. 
Bortolini (2013) descreve sobre o papel do gestor em relação aos recursos humanos, onde geralmente o diretor escolar, na sua formação para professor, não estudou a respeito de gestão de pessoas, desta maneira deve procurar estudar sobre, para um melhor desempenho na sua função. Relacionado aos recursos financeiros públicos, foi questionado quais a escola recebe, se existe muita burocracia para gastar e se são suficientes para a manutenção do prédio escolar e para a realização de projetos pedagógicos; a diretora respondeu que a escola recebe o PDDE - Programa Dinheiro Direto da Escola, educação básica e educação integral, que não existe tanta burocracia para gastar, uma vez que o dinheiro já vem com a destinação certa, porém os recursos não são suficientes, pois a escola é grande e estes recursos não são regulares.

Como gestora escolar, foi questionada se consegue realizar todas as tarefas diárias que lhe são exigidas em tempo hábil e quais os impedimentos; ela respondeu que não é fácil, mas que consegue e não encontra impedimentos. Foi lhe questionado também se considera importante ter uma equipe motivada e quais as maiores dificuldades encontradas para motivar a equipe e ter um bom clima organizacional; a gestora respondeu que considera sim muito importante ter uma equipe motivada, mas que a principal dificuldade é a falta de recursos humanos, pois acaba acumulando atividades para quem está trabalhando, o que torna mais difícil manter um bom clima organizacional, desta forma é necessário ter mais pessoas trabalhando na escola para dividir as tarefas.

Desta forma, Lück (2011) afirma que a gestão da cultura e do clima organizacional da escola constitui-se em fundamental dimensão de trabalho da gestão escolar, em vista do que os gestores escolares precisam dedicar grande e contínua atenção focada no modo coletivo de ser e de fazer da escola, em suas tendências de ação e reação, seus humores, suas relações interpessoais e grupais. Em seguida, foi questionada se considera que a escola onde trabalha possui um ensino de qualidade. a mesma falou que sim, pois nos últimos anos a escola não teve registro de evasão escolar, atende toda demanda existente no bairro, possui uma nota boa no Índice de Desenvolvimento da Educação Básica - IDEB, o município oferta um bom material escolar, as professoras e os funcionários participam sempre de capacitações, o que traz um bom resultado na qualidade de ensino. De acordo com Cortella (2017), a qualidade na educação passa, necessariamente, pela quantidade. Em uma democracia plena, quantidade é sinal de qualidade social e, se não se tem a quantidade total atendida, não se pode falar em qualidade. Afinal, a qualidade não se obtém por índices de rendimento em relação àqueles que frequentam escolas, mas pela diminuição drástica da evasão e pela democratização do acesso. 
Para finalizar a entrevista foi mencionado o objetivo central da pesquisa em questão, que são quais os principais desafios enfrentados como gestora escolar hoje na educação pública integral e como trabalha para solucioná-los; a gestora respondeu que são vários, mas que pode citar como os principais: os problemas que cada aluno traz consigo devido às demandas sociais de suas famílias; os recursos financeiros, que não são regulares; manter a equipe motivada com salas de aula lotadas e falta de pessoal para os serviços fundamentais; falta de autonomia para montar a equipe e tomar decisões; o excesso de projetos que não estão no plano anual e que surgem de repente, e que a Autarquia de Educação manda realizar, como campanhas sociais e ambientais, por exemplo. Mas o principal e maior de todos é a rotatividade de pessoal, prejudicando, desta forma, a regularidade do andamento escolar.

Com o intuito de solucionar estes desafios, a gestora relatou que conta com a participação efetiva de todos os membros pertencentes à escola, como pais, professores, funcionários, além da comunidade do entorno da escola, a sociedade civil organizada e o poder público, como a prefeitura, a Autarquia Municipal de Educação, o núcleo regional de educação, a promotoria e até mesmo a guarda municipal e a polícia militar quando necessário. Para finalizar, Bortolini (2013) destaca que a gestão democrática pode ser melhorada com a efetiva participação da comunidade escolar nas atividades educacionais, pois a presença e o envolvimento dos pais, alunos, professores e de toda equipe técnico pedagógica da escola é princípio fundamental para uma educação de qualidade e democrática.

\section{Considerações finais}

O objetivo do artigo era identificar e descrever os principais desafios que o gestor de uma escola pública municipal enfrenta atualmente e como trabalha para tentar solucionar tais desafios. Tais objetivos foram alcançados com o estudo de caso, onde foi realizada uma entrevista com vinte questões junto a uma diretora de uma determinada escola municipal. Neste estudo foram identificados que os principais desafios para esta gestora escolar são: os problemas sociais e familiares que cada aluno traz consigo; os recursos financeiros, que são irregulares; a dificuldade em manter a equipe motivada com salas de aula lotadas e a falta de pessoal para os serviços fundamentais; a falta de autonomia da gestora para montar a equipe e tomar decisões; o excesso de projetos que não estão no plano anual e que surgem de repente; e, por fim, a rotatividade de pessoal, que prejudica e muito o andamento da instituição de ensino. 
Para solucionar tais desafios elencados, a gestora conta com a participação efetiva de pais, professores, funcionários e a sociedade em geral, além do poder público.

A contribuição da pesquisa foi no sentido de compreender melhor o cotidiano das escolas públicas do município, pois a partir das dificuldades encontradas torna-se mais fácil solucionar tais problemas. A limitação da pesquisa em realizar este estudo de caso foi a de encontrar um gestor escolar que se comprometesse em falar a verdade, visto que como o cargo de gestor ainda é político-partidário, muitos evitam falar sobre a realidade nua e crua com receio de sofrerem perseguições ou até mesmo a perda do cargo. Como sugestão para futuros trabalhos relacionados a este tema, sugere-se elaborar estudos quantitativos com vários gestores escolares, desta forma observando se os desafios elencados serão os mesmos para todos, no entanto recomenda-se que para se fazer uma pesquisa desta abrangência, os gestores escolhidos devem estar no cargo por eleição da comunidade e não por nomeação política, pois assim não terão receio em falar a verdade ao pesquisador.

\section{REFERÊNCIAS}

BARROS, Aidil Jesus da Silveira; LEHFELD, Neide Aparecida de Souza. Fundamentos de Metodologia Científica. 2. ed. São Paulo: Makron Books do Brasil, 2000.

BORTOLINI, Jairo César. O papel do diretor na gestão democrática: desafios e possibilidades na prática da gestão escolar. Dourados: UNIGRAN, 2013.

BRASIL. Lei No. 9394/96, de 20 de dezembro de 1996. Estabelece as diretrizes e bases da educação nacional. Ministério da Educação. Brasília, 1996.

BRASIL. Constituição da República Federativa do Brasil (1988). Constituição Federal. In: CURIA, Luiz Roberto; CÉSPEDES, Lívia; NICOLETTI, Juliana. Vade Mecum universitário de direito Saraiva. 13. ed. São Paulo: Saraiva, 2012. p. 07-76.

CORTELLA, Mario Sergio. A escola e conhecimento: fundamentos epistemológicos e políticos. São Paulo: Cortez, 2017. Acesso em: 23 jan. 2018.

DENCKER, Ada de Freitas Maneti. Métodos e técnicas de pesquisa. São Paulo: Futura, 2001.

FERREIRA, Naura Syria Carapeto. Projeto político pedagógico. Curitiba: IBPEX, 2003.

FIALHO, Neusa Nogueira; TSUKAMOTO, Neide Mitiyo Shimazaki. Gestão democrática e educação de qualidade: desafios do gestor escolar. Florianópolis: UDESC X ANPED SUL, 2014.

FONSECA, João José Saraiva. Metodologia da pesquisa científica. Ceará: Universidade Estadual do Ceará, 2002. 
FREIRE, Paulo. Educação e mudança. 19. ed. Rio de Janeiro: Paz e Terra, 1979.

GRACINDO, Regina Vinhaes. O gestor escolar e as demandas da gestão democrática: exigências, práticas, perfil e formação. Brasília: Revista Retratos da Escola, v. 3. n. 4. 2009.

LÜCK, Heloísa. Dimensões da gestão escolar e suas competências. Curitiba: Editora Positivo, 2009.

LÜCK, Heloísa. Gestão da cultura e do clima organizacional da escola. 2. ed. Petrópolis: Vozes. V. V. (Série Cadernos de Gestão). 2011.

LÜCK, Heloísa. Liderança em gestão escolar. 8. ed. Petrópolis: Vozes, V. IV. (Série Cadernos de Gestão). 2012.

MARTINS, Gilberto de Andrade. Manual para Elaboração de Monografias e Dissertações. 3. ed. São Paulo: Atlas, 2002.

MEDEIROS, Fabíola de.; et al. Gestão patrimonial, financeira e relações de liderança. Guarapuava: Ed. da Unicentro, 2009.

MIRANDA, José Vicente. Metodologias Inovadoras aplicadas à Educação. Curitiba: IBPEX, 2003.

NESSLER, Nadia Cristina. MIRANDA, Natália Pergher. O Gestor Escolar e os desafios encontrados na função de direção. Três Passos: Universidade Federal de Santa Maria, 2013.

PARO, Vitor Henrique. Gestão democrática da escola pública. 3. ed. São Paulo: Ática, 2003.

PASQUINI, Adriana Salvaterra; SOUZA, Marcia Maria Previato de. Gestão escolar e organização do trabalho pedagógico na educação básica. Maringá: Ed. da Cesumar, 2012.

VALERIEN, Jean. Gestão da escola fundamental: subsídios para análise e sugestão de aperfeiçoamento. 7. ed. São Paulo: Cortez, 2001.

WERLE, Flávia Obino Corrêa. Novos tempos, novas designações e demandas: diretor, administrador ou gestor escolar. Porto Alegre: Revista UFRGS, v. 17. n. 2. 2001.

WITTMANN, Lauro Carlos. Práticas em Gestão Escolar. 20. ed. Curitiba: IBPEX, 2004.

ZANELLA, Liane Carly Hermes. Metodologia de estudo e de pesquisa em administração. 2. ed. Florianópolis: Departamento de Ciências da Administração, UFSC, 2012. 


\section{Como referenciar este artigo}

NASCIMENTO, Vanise Panont do; CHIUSOLI, Cláudio Luiz. O papel do gestor escolar: estudo de caso sobre os desafios da educação pública. Revista on line de Política e Gestão Educacional, Araraquara, v. 23, n. 2, p. 238-254, maio/ago., 2019. E-ISSN:1519-9029. DOI: 10.22633/rpge.v23i2.11997

Submetido em: 17/12/2018

Revisões requeridas: 20/12/2018

Aprovado em: 18/01/2019

Publicado em: 06/03/2019 